\title{
Blackberry-like lesion of the back: One Step melanoma surgery (OSMS) as possible treatment approach even when melanoma only suspected!?
}

\author{
Ivanka Temelkova ${ }^{1}$, Valeri Malev ${ }^{2}$, Georgi Tchernev ${ }^{*}$ \\ ${ }^{1}$ Onkoderma- Clinic for Dermatology, Venereology and Dermatologic Surgery, General Skobelev 26, 1606 Sofia \\ ${ }^{2}$ Medical student, Saint Kliment Ohridski University, Faculty of Medicine, Koziak street 1,1407 Sofia, Bulgaria
}

\begin{abstract}
Received: August 03, 2019; Accepted: August 05, 2019; Published: August 07, 2019
*Corresponding author: Prof. Dr. Georgi Tchernev, Onkoderma- Clinic for Dermatology, Venereology and Dermatologic Surgery, General Skobelev 26,1606 Sofia; E-mail: georgi_tchernev@yahoo.de
\end{abstract}

A 42 year old male patient visited the dermatological department with a complaint for suddenly appeared and curious looking lesion in the area of the back (fig. 1a-b). Respectively, the lesion was painless, but caused some cosmetic concerns. According to the anamnestic data several days before the clinical examination the formation has been treated by a surgeon with electrocautery, resulting in a partial remission of the lesion. A tissue sample has not been collected and no histopathological data was available at the time. During the dermatological examination the presence of blackberry like, around $5 \mathrm{~mm}$, elevated, lobulated lesion was established in the area of the back (fig. 1a-b). Additionally, circular redness was visualized around the lesion (fig. 1a-b). Based on clinic and dermatoscopy, the possibility of cutaneous hemangioma or melanoma was considered. Surgical removal of the lesion was performed with a direct operational safety margin of $1 \mathrm{~cm}$ in all directions. Subsequent histological examination revealed the presence of capillary hemangioma with clear resection lines.

Surgical removal of subcutaneous angiofibrolipoma from another part of the back has been performed several years ago.
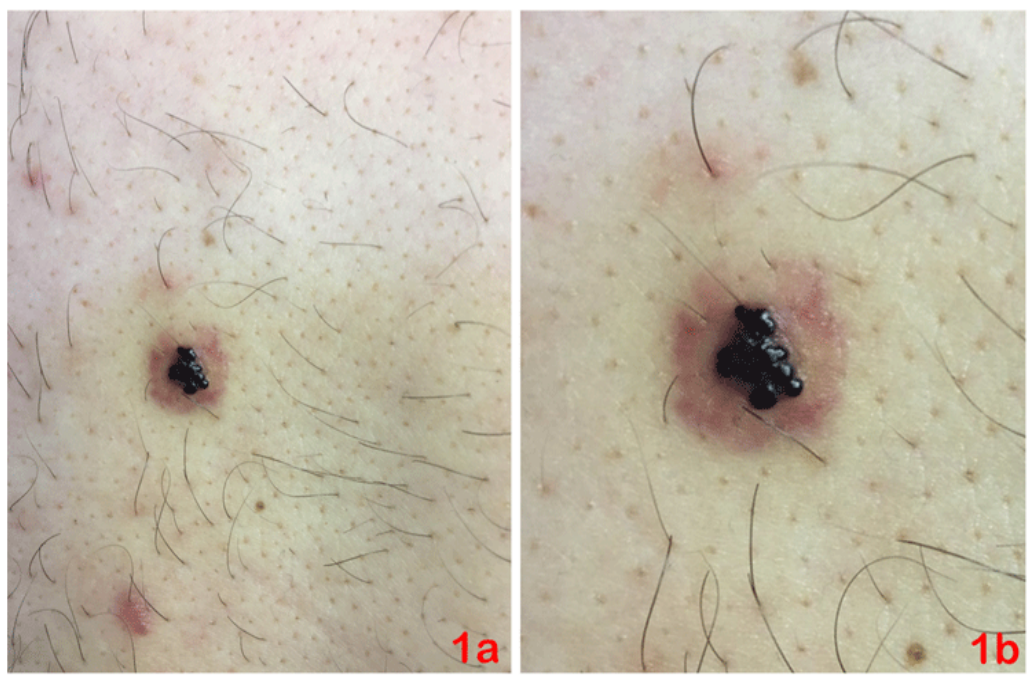

Fig. 1a-b: Clinical view of blackberry like capillary hemangioma in the area of the back

Lobular, capillary hemangiomas represent a rare acquired vascular formations, typically affecting the skin and mucous membranes [1]. However, it is extremely important to note that the diagnosis of such formations can therefore be challenging, especially as it may mimic more aggressive lesions, including malignancy [1]. In these cases, the possibility of melanoma should be included in the differential diagnostic aspect [2]. Therefore, the therapeutic approach for such type of lesions should be unified and consistent with the differential diagnosis. In case of suspected nodular melanoma or melanoma below $1 \mathrm{~mm}$ thin (as a possible differential diagnosis in our patient also), it would be good to think with one step forward, namely, performance of 
initial resection of the lesion with a surgical safety margin of $1 \mathrm{~cm}$ (within the one step melanoma surgery (OSMS) model), which in turn: 1) is adequate for the vascular lesion and 2) in the event of thin melanoma, this surgical safety margin is also adequate and does not require re-excision $[3,4]$.

In practice, considering a differential diagnosis with OSMS melanoma treatment methodology, a case solution is provided within one surgical session [5].

\section{References}

1. Chan C, Iv M, Fischbein N, Dahmoush H. Lobular capillary hemangioma of the mandible: A case report. Clin Imaging. 2018; 50:246-249. doi: 10.1016/j.clinimag.2018.04.012

2. Bondi EE and Clark WH Jr. Clinical differentiation of adult-onset cavernous angioma from nodular malignant melanoma. Arch Dermatol. 1980;116(3):299-300.
3. Tchernev G and Temelkova I. The One Step Melanoma Surgery (OSMS): A New Chance for More Adequate Surgical Treatment of Melanoma Patients!? Open Access Maced J Med Sci. 2019;7(3):504506. doi: 10.3889/oamjms.2019.147

4. Swetter SM, Tsao H, Bichakjian CK, Curiel-Lewandrowski C, Elder DE, Gershenwald JE, et al . Guidelines of care for the management of primary cutaneous melanoma. J Am Acad Dermatol.2019;80(1):208-250. doi: 10.1016/j.jaad.2018.08.055

5. Tchernev G and Temelkova I. Comparative Analysis of the "Scholastic" Recommendations of the AJCC From 2011 for the Surgical Treatment of Cutaneous Melanoma with the Newly Suggested Guidelines for OSMS From the Bulgarian Society For Dermatologic Surgery! Open Access Maced J Med Sci. 2018;6(12):2369-2372. doi: 10.3889/ oamjms.2018.511 